\title{
PKM KELOMPOK PETANI PULAU-PULAU KECIL PEMBUAT BIOCHAR UNTUK PENINGKATAN PRODUKSI PALAWIJA
}

\author{
${ }^{1)}$ Ida Ekawati, ${ }^{2)}$ Isdiantoni, ${ }^{3)}$ Purwati Ratna W \\ ${ }^{1,2,3)}$ Program Studi Agribisnis, Fakultas Pertanian, Universitas Wiraraja \\ 1,2,3) Jl. Raya Sumenep Pamekasan Km. 5, Patean, Sumenep, Indonesia \\ E-mail : idaekawati@wiraraja.ac.id, isdiantoni@wiraraja.ac.id,purwatiratna@wiraraja.ac.id
}

\begin{abstract}
ABSTRAK
Pengetahuan petani di pulau pulau kecil dan masyarakat petani pada umumnya tentang pengelolaan limbah pertanian untuk bahan penyubur tanah masih rendah. Limbah pertanian sering dibakar di lahan sehingga hanya abu yang dihasilkan. Selain itu, pembakaran limbah pertanian mengakibatkan unsur hara yang terkandung banyak yang hilang dan dapat mematikan mikroorganisme yang dapat menyuburkan tanah. Padahal limbah tersebut dapat dimanfaatkan untuk membuat biochar dengan sedikit mengubah cara pembakaran limbah tersebut. Biochar dapat dimanfaatkan untuk mengatasi masalah kesuburan tanah guna mendukung keberlanjutan pangan.Tujuan kegiatan pengabdian masyarakat ini adalah a) mengenalkan manfaat biochar sebagai bahan penyubur tanah kepada petani di pulau kecil dan pemuda tanidi Desa Manding Laok; b) meningkatkan ketrampilan petani dan pemuda tani dalam pembuatan biochar metode tungku sederhana dan drum pembakaran tertutup melalui pelatihan;; c) aplikasi biochar pada media tanam untuk tanaman sayuran. Metode PLA (Participatory Learning and Action) diterapkan pada pelaksanaan penyuluhan, pelatihan, demo plot aplikasi biochar pada media tanam sayuran.Luaran yang dihasilkan yaitu: a) Pengetahuan petani mitra terhadap biochar dan manfaatnya meningkat $72 \%$, b) petani mampu dan dapat membuat biochar; c) petani mitra mau mengaplikasikan biochar untuk meningkatkan kesuburan lahan dan produksi tanaman sebanyak 2 orang petani. Kegiatan ini perlu tindak lanjut pemanfaatan asap pembakaran sebagai asap cair untuk biopestisida.
\end{abstract}

Kata Kunci: biochar, tungku sederhana, pembakaran tertutup, peningkatan produktivitas.

\section{ABSTRACT}

Knowledge of farmers in small islands and farming communities in general about the management of agricultural waste for soil fertilizing agents is still low. Agricultural waste is often burned in the fields so that only ash is produced. In addition, the burning of agricultural waste results in the loss of many nutrients contained and can kill microorganisms that can fertilize the soil. Whereas the waste can be used to make biochar by slightly changing the way the waste is burned. Biochar can be used to overcome soil fertility problems to support food sustainability. The objectives of this community service activity are a) to introduce the benefits of biochar as a soil fertilizer to small island farmers and young farmers in Manding Laok Village; $b$ ) improve the skills of farmers and young farmers in making biochar using the simple stove method and closedburning drum through training; c) application of biochar in growing media for vegetable crops. The PLA (Participatory Learning and Action) method is applied to the implementation of counseling, training, and demo plots of biochar application on vegetable growing media.; c) partner farmers want to apply biochar to increase land fertility and crop production as many as 2 farmers. This activity needs a follow-up on the use of combustion smoke as liquid smoke for biopesticides.

Keyword: biochar, simple furnace, closed combustion, increased productivity

\section{PENDAHULUAN}

\section{Pendahuluan}

Biochar adalah produk kaya karbon hasil pembakaran biomassa seperti kayu, seresah daun kering, ranting pohon, limbah panen, pupuk kandang dalam wadah tertutup dengan kondisi sedikit atau tanpa udara tersedia. Secara teknis, biochar diproduksi melalui dekomposisi termal dari bahan organik dengan persediaan oksigen terbatas, dan pada suhu kurang dari $700{ }^{\circ} \mathrm{C}$ (Lehmann and Joshep, 2011). Pembuatannya mirip dengan pembuatan arang, namun tujuannya berbeda.Biochar digunakan sebagai bahan pembenah tanah untuk meningkatkan produktivitas tanah dan penyimpanan karbon tanah, sementara arang digunakan 
untuk energi. Menurut Balai Penelitian Tanah fungsi biochar adalah 1) meningkatkan ketersediaan hara; 2) meretensi hara;3) meretensi air; 4) meningkatkan KTK; 5) menciptakan habitat yang baik bagi perkembangan mikroorganisme simbiotik seperti mikoriza karena kemampuannya dalam menahan air dan udara serta menciptakan lingkungan yang bersifat netral khususnya pada tanah-tanah masam; 6) meningkatkan produksi tanaman pangan; 7) mengurangi laju emisi CO2 dan mengakumulasi karbon dalam jumlah yang cukup besar.

Petani di pulau pulau kecil wilayah Kabupaten Sumenep, seperti di pulau Poteran merupakan petani subsisten, yang artinya petani menanam palawija hanya untuk mencukupi kebutuhan pangan rumah tangga. Hasil panen tidak dijual tetapi disimpan untuk persediaan pangan selama satu tahun. Ketahanan pangan rumah tangga tergantung pada hasil panen dan sangat rapuh.Hal ini disebabkan hasil panen rendah serta ketersediaan pangan juga tergantung pada supply pangan dari luar pulau. Bila musim ombak suplay pangan terancam ketersediaannya.

Rendahnya hasil panen dipicu rendahnya kesuburan lahan, yang diakibatkan oleh kebiasaan petani membakar seresah daun, ranting, limbah panen di lahan, bahkan pupuk kandang/kotoran ternak tidak dikomposkan namun dibakar terlebih dahulu sebelum diaplikasikan ke lahan.Pembakarannya sempurna dan dalam kondisi terbuka (cukup oksigen), sehingga hanya dihasilkan abu, dan unsur-unsur hara yang terkandung dalam bahan organik tersebut hilang.Kebiasaan petani membakar bahan organik mengakibatkan lahan pertanian kurang subur. Hasil survey Ekawati dan Isdiantoni (2017) menunjukkan bahwa produksi tanaman pangan di Pulau Poteran rendah, sebagai contoh jagung yang ditanam di musim penghujan hanya menghasilkan 1,33 ton/ha.

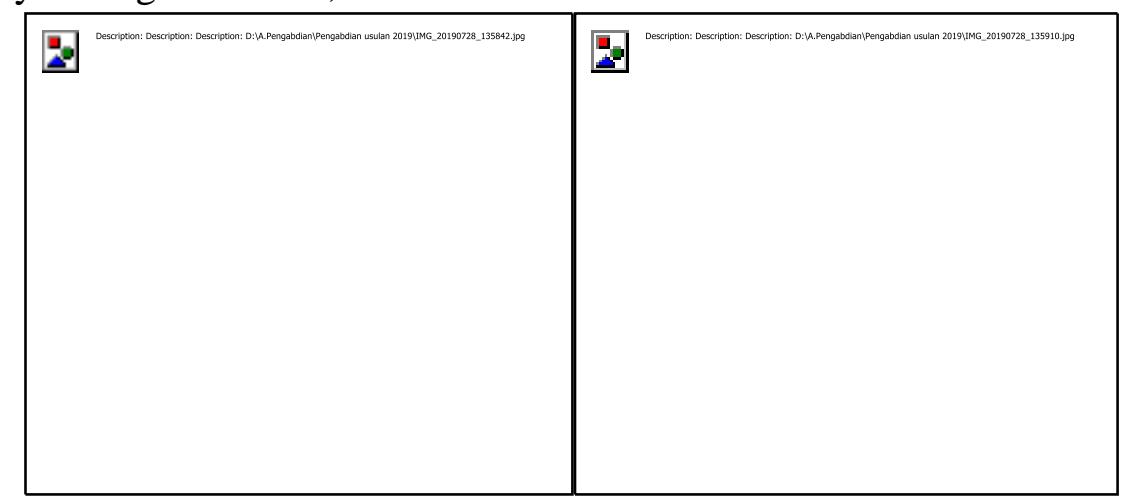

Gambar 1. Pembakaran Seresah Daun dan Limbah Panen di Lahan Desa Talango

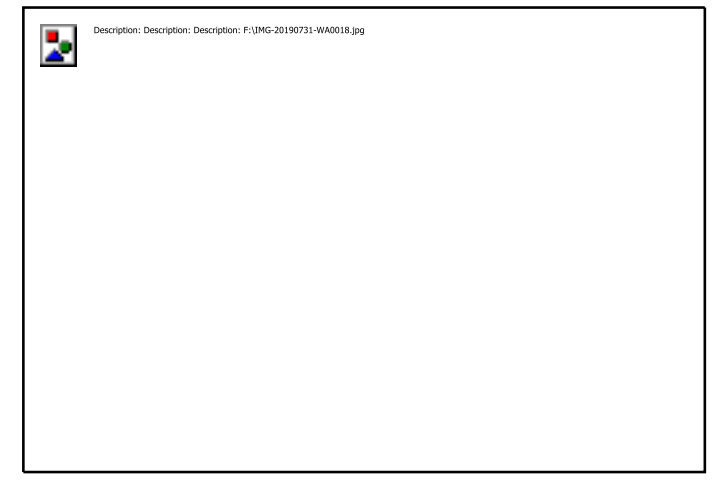

Gambar 2. Pembakaran Pupuk Kandang Kotoran Sapi

Kebiasaan petani ini perlu diubah dari pembakaran sempurna bahan organik menjadi pembakaran tidak sempurna bahan organik sehingga dihasilkan sejenis arang kaya karbon yang 
disebut dengan biochar.Harapannya petani tidak lagi menghasilkan abu tetapi menghasilkan biochar untuk diaplikasikan ke lahan guna meningkatkan produktivitas lahan dan tanaman guna mendukung keberlanjutan produksi pangan.

Untuk keberlanjutan penyediaan pangan, hal krusial yang perlu dilakukan yaitu peningkatan produktivitas lahan dan produktivitas tanaman dengan aplikasi biochar.Penelitian aplikasi biochar untuk meningkatkan produksi tanaman telah banyak dilakukan. Aplikasi biochar dapat meningkatkan produksi jagung manis sebesar $30 \%$ (Nurhidayati dan Mariati, 2014), sementara aplikasi secara berturut turut selama 3 tahundapat meningkatkan produksi jagung hingga 140\% (Major et al., 2010). Tanaman padi yang ditanam di tanah sulfat masam juga meningkat produksinya akibat perlakuan pemberian biochar dan biomassa Cromolaena odorata (Masulili, Utomo, dan Syekhfani, 2010).Penelitian lainnya menunjukkan bahwa kondisi biologi tanah, sifat fisik tanah, dan sifat kimia tanah diperbaiki dengan aplikasi biochar ke tanah (Nurida, 2014).Oleh karena itu, produksi pangan di pulau pulau kecil juga dapat ditingkatkan dengan aplikasi biochar yang dapat dibuat petani dengan memanfaatkan limbah panen yang berlimpah.

\section{METODE PELAKSANAAN}

Kegiatan pengabdian kepada masyarakat ini dilaksanakan pada bulan Juli sampai dengan bulan Nopember 2020, mulai dari persiapan hingga pelaksanaan pelatihan dan aplikasi biochar pada media tanam. Lokasi kegiatan pengabdian masyarakat dilaksanakan di Desa Talango Dusun Sekolahan Pulau Poteran Kabupaten Sumenep dan di Desa Manding Laok Kecamatan Manding Kabupaten Sumenep. Sebagai sasaran adalah Petani dusun Sekolahan Desa Talango, dan Kelompok Pemuda Tani Desa Manding Laok Kecamatan Manding yang beranggotakan 30 pemuda tani. Pengabdian ini dilakukan dengan pelatihan pembuatan biochar dan menerapkannya pada usahatani petani yang digunakan sebagai sampel. Kerangka kerja kegiatan pelaksanaan pengabdian ini disajikan pada Gambar 3.

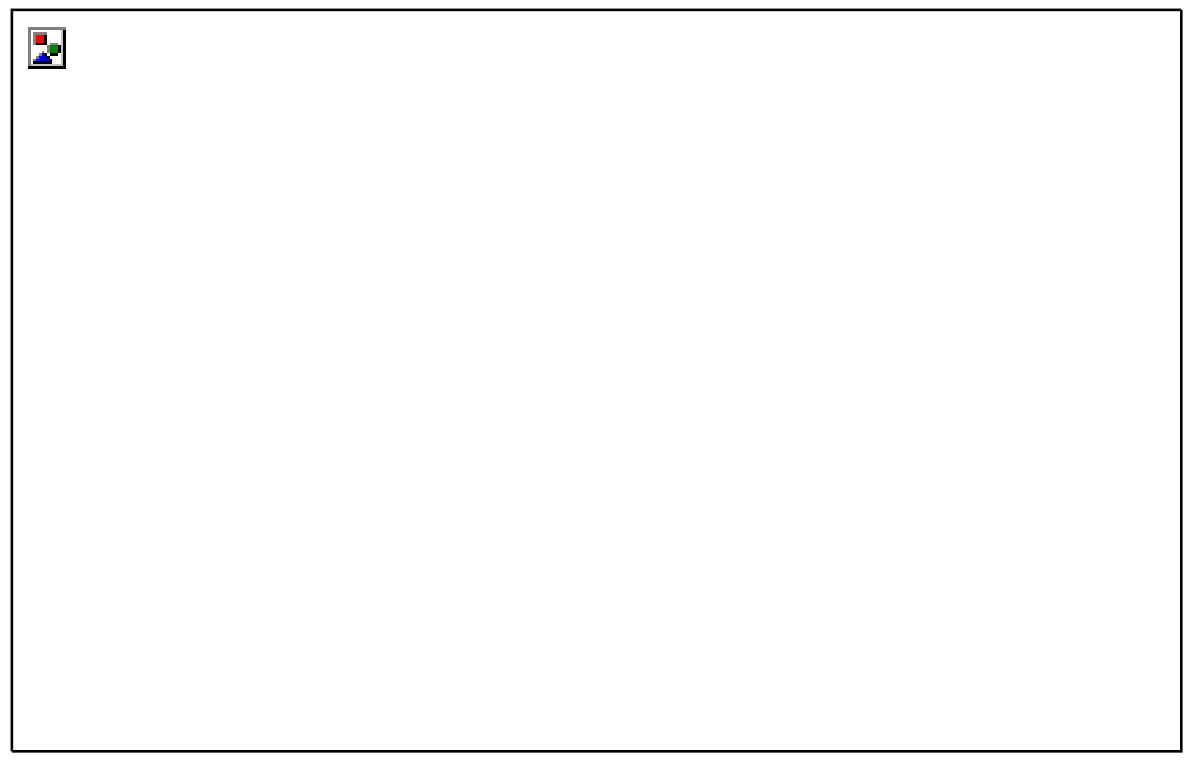

Gambar 3. Kerangka Kerja Kegiatan Pengabdian

Metode pelaksanaan kegiatan Program Kemitraan Masyarakat ini melalui tahapan sebagai berikut: 
a. Penyuluhan pengenalan biochar dan manfaatnya dengan metode pendidikan orang dewasa.Penyuluhan ini dilaksanakan secara tatap muka individu kepada petani potensial di Dusun Sekolahan Desa Talango Kecamatan Talango, dengan harapan dapat menularkan pengetahuannya kepada petani lainnya. Selain itu penyuluhan juga dilakukan kepada kelompok pemuda tani "Jokotole" Desa Manding Laok Kecamatan Manding melalui daring, dengan menyebarkan brosur biochar dan manfaatnya. Hal ini karena terkendala kondisi pandemi Covid 19;

b. Pelatihan pembuatan biochar dari limbah panen yang tidak digunakan untuk pakan ternak seperti kulit kacang dan tongkol jagung. Metode yang digunakan PLA (Participatory Learning and Action), yang mana semua peserta aktif diskusi dan praktek pembuatan biochar dengan metode tungku tanah sederhana dan menggunakan alat drum pembakaran tertutup. Tahapan pelaksanaan pelatihan sebagai berikut: 1) merancang alat drum pembakaran dengan pipa udara pembakaran, 2) melakukan uji coba alat, 3) mempersiapkan peralatan pelatihan, nara sumber, dan tempat pelatihan, 4) melaksanakan pelatihan, 5) melakukan pendampingan petani yang membuat biochar.

c. Aplikasi biochar pada tanaman sayuran di lahan petani di Desa Manding. Biochar diaplikasikan pada media tanam polibag untuk tanaman sawi dan kangkung. Media tanam terdiri atas campuran tanah, kompos kotoran ternak, dan biochar dengan perbandingan 1:1:1. Kegiatan ini memberikan gambaran dan pengalaman bagi pemuda tani dalam aplikasi biochar sebagai campuran media tanam sayuran.

d. Evaluasi kegiatan penyuluhan dan pelatihan pembuatan biochar dilakukan setelah kegiatan selesai, dengan cara memberikan pertanyaan terkait biochar, manfaat, dan cara pembuatan.

\section{HASIL}

Keberlanjutan produksi pangan menjadi perhatian semua pihak, mengingat kebutuhan pangan yang semakin meningkat sejalan dengan meningkatnya jumlah penduduk dunia yang diperkirakan meningkat menjadi 9,7 milyar di tahun 2050 (Ritung, 2010). Permasalahan ini perlu disikapi dengan berpupaya meningkatkan produksi pangan dan peningkatan produktifitas lahan. Berbagai cara dapat dilakukan, salah satu cara meningkatkan produktivitas lahan adalah aplikasi biochar sebagai pembenah tanah. Masalah ini tentunya perlu deseminasi teknologi biochar kepada petani agar bisa diterapkannya dalam budidaya tanaman. Dengan demikian diharapkan dapat menyokong keberlanjutan produksi pangan. Kegiatan deseminasi biochar dapat dilakukan dengan melakukan kegiatan penyuluhan, pelatihan, dan pendampingan pembuatan biochar dan aplikasinya di lahan.

\section{Penyuluhan manfaat biochar}

Kondisi pandemi Covid 19 menjadi kendala dalam melaksanakan penyuluhan, sehingga perlu dicarikan solusinya. Penggunaan teknologi informasi menjadi suatu solusi. Untuk melaksanakan penyuluhan dengan menggunakan teknologi informasi pada petani di pulau pulau kecil mengalami kendala yaitu petani sebagian besar berusia lanjut dan tidak menguasai teknologi informasi. Oleh karenanya penyuluhan dilakukan secara tatap muka individu hanya kepada tiga petani yang potensial mau meningkatkan pengetahuannya. Harapannya petani tersebut mau menularkan pengetahuannya kepada petani lain. Untuk lebih tersebarnya pengetahuan biochar kepada petani maka, dicari kelompok pemuda tani di wilayah lain dan terpilih kelompok pemuda tani di kecamatan Manding. Kegiatan penyuluhan dilakukan secara 
daring, mengingat pada kondisi pandemi Covid 19. Leafled manfaat biochar dikirim melalui whatsaap serta diberikan penjelasan terkait dengan manfaat biochar dan cara pembuatannya. Respon petani muda cukup bagus, dari 25 anggota kelompok Pemuda Taniyang memiliki handphone android semuanya memberikan respon baik. Semua pemuda tani menjadi tahu biochar dan manfaatnya serta cara pembuatannya. Pemuda Tani yang sebelumnya tidak mengetahui biochar akhirnya meningkat pengetahuannya. Pemuda tani yang tertarik dan ingin mencoba sebanyak 72\%. Menurut petani limbah pertanian seperti tongkol jagung, ranting pohon, seresah lebih baik dibuat biochar dari pada dibakar menjadi abu. Hal ini merupakan hasil dari kegiatan penyuluhanSelain itu, petani ingin membuktikan manfaat biochar dengan mencoba mengaplikasikannya pada budidaya tanaman setelah mendapatkan bukti bahwa biochar memperbaiki pertumbuhan tanaman. Adanya perubahan pengetahuan ini akan mempermudah petani menerapkan teknologi biochar. Hal ini sejalan dengan hasil penelitian Dewi dan Rahmawati (2019) terkait dengan adopsi teknologi budidaya kakao. Selain itu, frekuensi kontak dengan lembaga penyuluhan mempengaruhi adopsi teknologi (Chandio dan Yuansheng, 2018).

\section{Pelatihan pembuatan biochar dengan tungku sederhana}

Penggunaan teknologi sederhana dalam pelatihan ini dimaksudkan agar mudah diterima oleh petani. Teknologi yang sederhana tidak rumit akan mudah diadopsi oleh petani (Ekawati, Isdiantoni, dan Purwanto, 2011). Pembuatan biochar dengan tungku sederhana tidakrumit mudah dilaksanakan. Petani dengan mudah dapat mengikuti pelatihan dan aktif terlibat dalam melaksanakan pembuatan biochar. Hal ini menambah pemahaman dan ketrampilan petani dalam membuat biochar. Petani berpendapat bahwa pembuatan biochar mudah dan mereka mampu membuat sendiri. Pembuatan biochar tongkol jagung hanya membutuhkan waktu 1,5 jam. Biochar yang dihasilkan merata atau homogen. Hal ini merupakan indikator kualitas biochar yang baik.

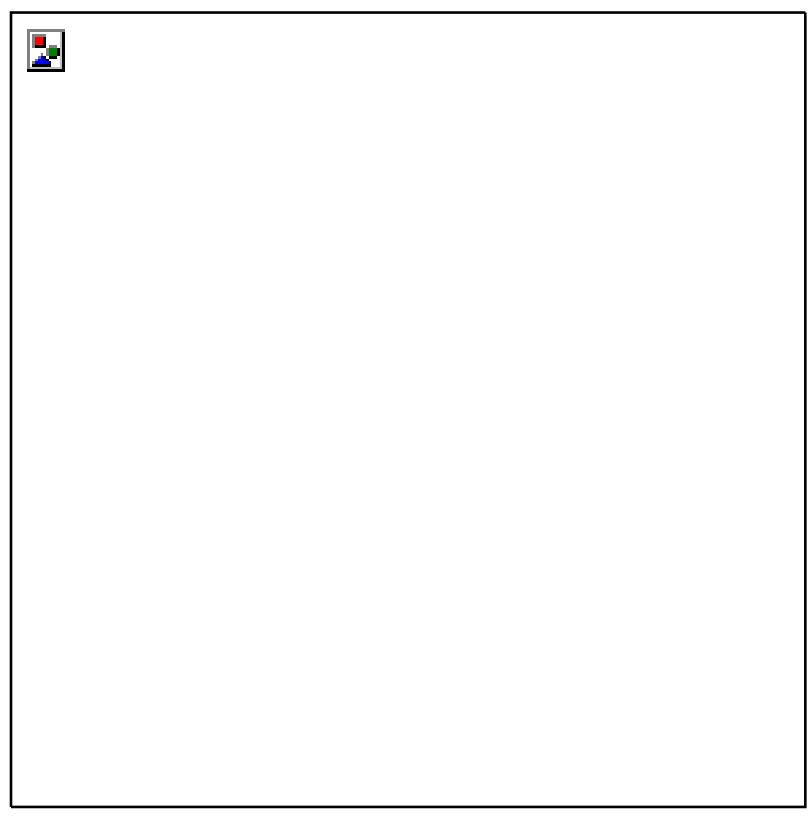

Gambar 4. Biochar hasil pembakaran tongkol jagung

\begin{tabular}{|c|c|c|}
\hline & 圈 & \\
\hline$\overline{\mathrm{DOI}}$ : https://doi.org/10.36341/jpm| & \begin{tabular}{|l}
$\mathrm{v} 5 \mathrm{i} 2.2172$ \\
$\mathrm{n}$
\end{tabular} & $\begin{array}{l}\text { PenulisPertama : Ida Ekawati } \\
\end{array}$ \\
\hline
\end{tabular}


Gambar 5. Petani aktif terlibat dalam pembuatan biochar tongkol jagung

Sebanyak satu karung tongkol jagung $(+/-12 \mathrm{~kg})$ dihasilkan biochar sebanyak $45 \%$. Tongkol jagung yang telah menjadi arangini setelah dimatikan apinya dengan disiram air dapat diaplikasikan ke lahan. Biochar ini dapat memperbaiki sifat fisik tanah dengan terbentuknya rongga rongga untuk memperlancar aerasi. Kesuburan kimia juga diperbaiki dengan aplikasi biochar ke dalam tanah (Siringoringo dan Siregar, 2011; Nartey dan Zhao, 2014). Teknologi pembuatan biochar yang mudah ini mendorong petani untuk membuatnya sendiri. Apabila biochar dapat diadopsi petani, selanjutnya dapat diperkenalkan dengan pembuatan biochar dengan teknologi retorklin dan dikembangkan secara komersiil guna menambah pendapatan pemuda tani.

\section{Pelatihan pembuatan biochar dengan metode tong pembakaran tertutup}

Pada pelatihan ini petani praktek secara langsung pembuatan tong pembakaran tertutup dan praktek pembuatan biochar dengan alat tersebut. Petani terlibat langsung pada kegiatan ini, sehingga dapat melihat sendiri dan praktek langsung pembuatan biochar. Hal ini menambah pemahaman dan ketrampilan petani dalam pembuatan biochar. Hasil evaluasi kegiatan menunjukan bahwa petani paham dan mampu untuk membuat biochar dengan metode tong pembakaran tertutup. Menurut petani metode ini bisa mengurangi asap yang muncul.

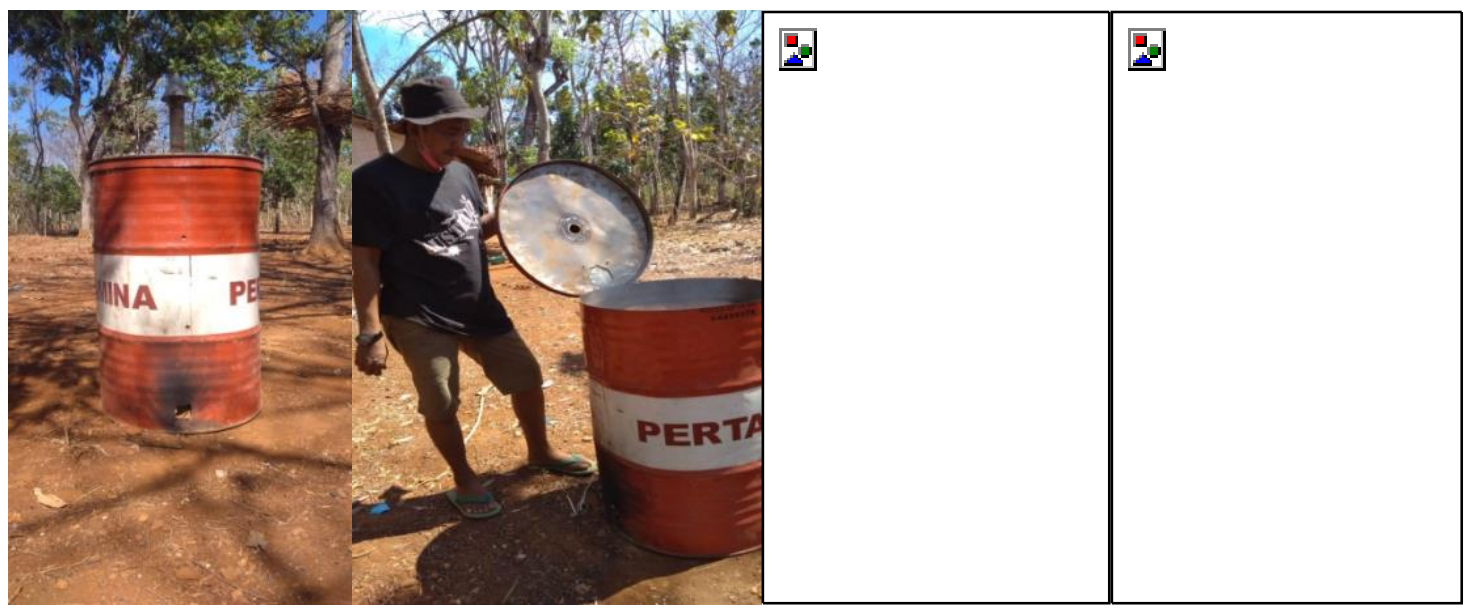

Gambar 6. Drum pembakaran sistem tertutup dan pembuatan biochar tongkol jagung

Kapasitas drum pembakaran mencapai $32 \mathrm{~kg}$ tongkol jagung. Biochar terbentuk setelah pembakaran selama 3,5 jam.Biochar yang dihasilkan sebanyak 40\% dari total berat bahan dasar berupa campuran tongkol jagung, tempurung kelapa dan batang ketela pohon. Biochar yang 
mengandung karbon ini dapat diaplikasikan ke lahan sebagai bahan pembenah tanah untuk meningkatkan kesuburan tanah dan meningkatkan hasil pangan (Scholz et al., 2014). Bahan ini juga dapat dimanfaatkan sebagai campuran media tanam dalam pot untuk budidaya sayuran atau buah.

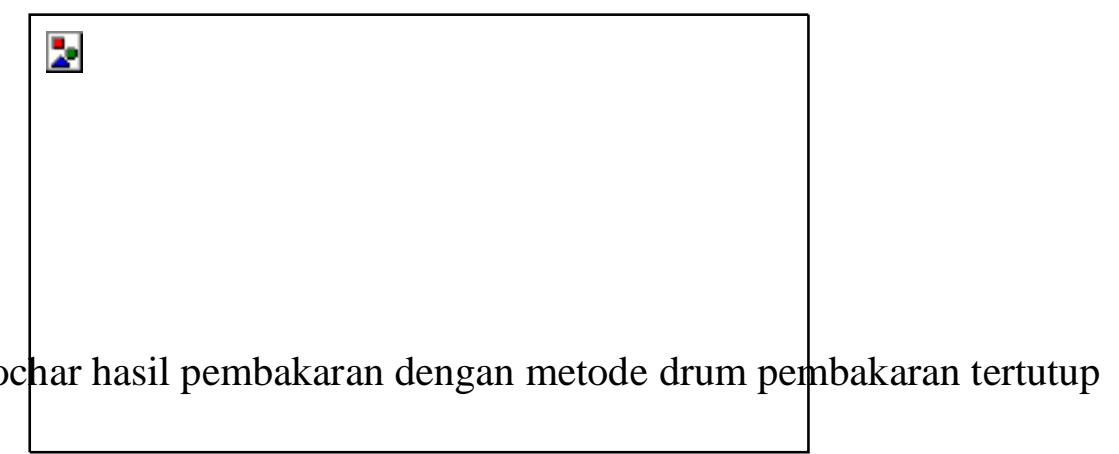

Dari hasil pembakaran limbah pertanian tersebut, biochar nampak homogen atau seragam sebagai akibat panas dalam drum merata.

\section{Aplikasi biochar pada tanaman kangkung dan sawi}

Biochar tongkol jagung hasil pelatihan diaplikasikan pada media tanam untuk tanaman kangkung dan sawi. Salah satu anggota kelompok pemuda tani bersedia untuk mencoba aplikasi biochar pada media tanam sayuran kangkung dan sawi. Hal ini sebagai upaya membuktikan bahwa biochar dapat digunakan untuk meningkatkan kesuburan tanah. Pertumbuhan tanaman sawi pada media yang diberi biochar menunjukkan bahwa daun sawi lebih lebar dibandingkan dengan tanaman sawi pada media tanah tanpa biochar, demikian pula pertumbuhan tanaman kangkung lebih baik.Hal ini menambah keyakinan petani akan manfaat biochar. Aplikasi biochar pada media pembibitan S. Leprosulamenghasilkan tinggi bibit dan jumlah daun lebih banyak dibandingkan tanpa biochar sebagai akibat media lebih porus (Syahrinudin et al., 2018).
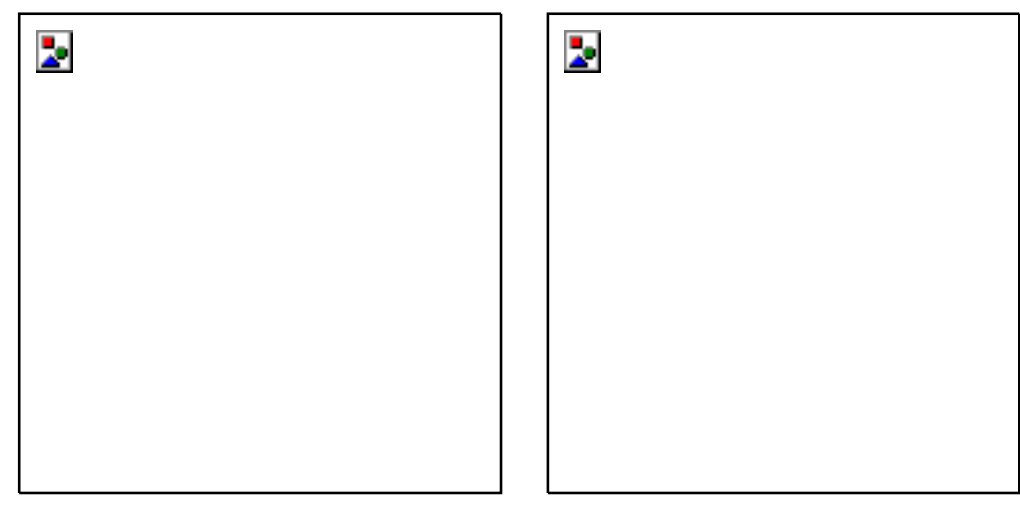

Gambar 8. Persiapan media tanam (a), pertumbuhan sawi dan kangkung (b)

\section{KESIMPULAN}

Kegiatan pengabdian kepada masyarakat untuk petani di pulau pulau kecil dan pemuda tani dapat disimpulkan bahwa pengetahuan dan ketrampilan pemuda tani meningkat dan sebanyak $72 \%$ pemuda tani tertarik ingin mencoba membuat biochar dengan metode tungku sederhana. Petani di Dusun sekolahan Desa Talango pulau Poteran memahami manfaat biochar dan dapat membuat biochar dengan metode drum pembakaran tertutup. 
Sebagai respon terhadap keluhan petani yaitu munculnya asap yang banyak, maka kegiatan lanjutan yang diperlukan adalah pemanfaatan asap pembakaran untuk asap cair yang berguna sebagai biopestisida. Selain itu, Deseminasi manfaat biochar perlu dilakukan secara kontinyu kepada masyarakat tani lainnya agar muncul permintaan akan biochar, sehingga memberikan peluang usaha untuk menambah pendapatan petani. Demikian pula untuk menunjang keberlanjutan produksi pangan.

\section{DAFTAR PUSTAKA}

[1] A. A. Chandio and J. Yuansheng, "Determinants of Adoption of Improved Rice Varieties in Northern Sindh, Pakistan," Rice Sci., vol. 25, no. 2, pp. 103-110, 2018, doi: 10.1016/j.rsci.2017.10.003.

[2] Y. A. Dewi and R. Rahmawati, "Faktor-Faktor Yang Mempengaruhi Adopsi Teknologi Budidaya Kakao Di Nusa Tenggara Barat,” J. Pengkaj. dan Pengemb. Teknol. Pertan., vol. 22, no. 2, p. 185, 2020, doi: 10.21082/jpptp.v22n2.2019.p198-214.

[3] I. Ekawati and dan P. Isdiantoni, "FAKTOR-FAKTOR YANG MENDASARI PETANI DI KABUPATEN SUMENEP,” vol. 8, pp. 8-14, 2011.

[4] I. Ekawati and Isdiantoni, "Pertanaman Campuran Lahan Kering Spesifik Pulau Poteran: Penyediaan Pangan dan Pakan Ternak," Prosiding Seminar Nasional Hasil Penelitian Sosial Ekonomi Pertanian, 2017.

[5] J. Lehmann, M. C. Rillig, J. Thies, C. A. Masiello, W. C. Hockaday, and D. Crowley, "Biochar effects on soil biota - A review," Soil Biol. Biochem., vol. 43, no. 9, pp. 18121836, 2011, doi: 10.1016/j.soilbio.2011.04.022.

[6] J. Major, M. Rondon, D. Molina, S. J. Riha, and J. Lehmann, "Maize yield and nutrition during 4 years after biochar application to a Colombian savanna oxisol," pp. 117-128, 2010, doi: 10.1007/s11104-010-0327-0.

[7] and S. Masulili, A., W. Utomo, Journal of Agricultural Science, vol. 53, no. 9. 2010.

[8] O. D. Nartey and B. Zhao, "Biochar preparation, characterization, and adsorptive capacity and its effect on bioavailability of contaminants: An overview," Adv. Mater. Sci. Eng., vol. 2014, 2014, doi: 10.1155/2014/715398.

[9] Nurhidayati dan Mariati, “J OURNAL OF D EGRADED AND M INING L ANDS M ANAGEMENT Utilization of maize cob biochar and rice husk charcoal as soil amendments for improving acid soil fertility and productivity," vol. 2, no. 1, pp. 223-230, 2014, doi: 10.15243/jdmlm.2014.021.223.

[10] N. L. Nurida, "Potensi Pemanfaatan Biochar untuk Rehabilitasi Lahan Kering di Indonesia Potency of Utilizing Biochar for Dryland Rehabilitation in Indonesia," J. Sumberd. Lahan, vol. Edisi Khus, pp. 57-68, 2014.

[11] Ritung, S. "Lahan Sawah dan Kecukupan Produksi Bahan Pangan," J. Sumberd. Lahan, vol. 4, no. 1, pp. 27-38, 2010.

[12] S. B. Scholz, T. Sembres, K. Roberts, T. Whitman, K. Wilson, and J. Lehmann, Biochar Systems for Smallholders in Developing Countries. 2014.

[13] H. H. Siringoringo and C. A. Siregar, "Pengaruh aplikasi arang terhadap pertumbuhan awal," J. Penelit. Hutan dan Konserv. Alam, vol. 8, no. 1, pp. 65-85, 2011.

[14] A. Wijaya, T. Butarbutar, and W. Hartati, "Biochar Yang Diproduksi Dengan Tungku Drum Tertutup Retort," vol. 2, no. 1, pp. 49-58, 2018. 